\title{
Study on Risk Control in Age Care Institutions Combination of Medicine and Nursing
}

\author{
Fengying Zhang ${ }^{1} \quad$ Jianhui Kong $^{2}$ Yimao Zhou $^{3}$ Zongfang Zhou ${ }^{4}$ \\ ${ }^{1}$ West China Hospital/West China School of Nursing, Sichuan University; ${ }^{2}$ Sichuan \\ Zhongfa Law Firm; ${ }^{3}$ Suzhou Huiyutong Date Science and Technology Ltd.; ${ }^{4}$ University \\ of Electronic Science and Technology of China
}

\begin{abstract}
"Combination of medicine and nursing" is a new pattern of providing for the aged in China in recent years. Because of the high uncertainty of the elderly and the existence of the risk of age care institutions, this paper explores the risk analysis and risk management strategies of age care institutions. Risk control strategy: setting up the management system of age care institutions to improve the standard, making the elderly management plan; implementing institutions risk prevention according to the risk management of stage; improving the medical staff awareness of risk prevention; establishing inventory management, reduce the technical risk and carry out the effective way of continuing education; the establishment of medical insurance system and fund risk, establishing risk sharing mechanism.
\end{abstract}

\section{Keywords}

Combination of medicine and nursing; Age care Institutes; Risk

\section{医养结合养老机构服务应用风险控制研究}

\author{
张凤英 ${ }^{1}$ 孔建会 ${ }^{2}$ 周一禁 ${ }^{3}$ 周宗放 \\ 1 四川大学华西医院/华西护理学院, 成都 $610041 ;{ }^{2}$ 西南民族大学法学院, 成都 \\ $610041{ }^{3}$ 苏州汇誉通数据科技有限公司, 苏州 215123 ; \\ ${ }^{4}$ 电子科技大学经济与管理学院, 成都 610041
}

摘要：“医养结合” 是近年来在我国逐渐发展起来的一种新型养老模式。由于老年人的状况 具有较高的不确定性及养老机构运行风险的存在，本文拟开展养老机构行业风险分析和风险 管理策略探索。风险防控策略：建立健全规范的养老机构管理制度，制订老人院管理预案; 按风险管理阶段进行养老机构风险防范; 提高医务人员风险防范意识; 建立清单式管理, 降 低非技术风险开展有效的继续教育途径; 设立保险制度及医疗风险基金，建立风险共担机 制。

关键词：医养结合；养老机构；风险

\section{1. 引言}

上世纪 80 年代, 美欧发达国家已逐 步进入老龄化社会，开始积极采用信息化 
丁十x讨医疗系统进行资源整合 ${ }^{119}$ ，政付装 持社区和家庭结合提供高质量的老人长期 护理服务。为提供高质量的医疗服务, 丹 麦、荷兰、瑞士和英国等国家制定激励计 划促进机构养老、社区养老、居家养老等 不同养老服务类型的提供者协作运营 ${ }^{[2],}$ 现养老模式已发展较为成熟。美国自 20 世纪 80 年代末以社区卫生信息网络为主 建立国家健康信息网络, 实现医疗机构间 的信息共享 ${ }^{[3]}$,为改进和提高医疗卫生服 务, 使在医疗卫生决策者, 包括客户和患 者都能够共享医疗卫生信息, 从而改进和 提高医疗卫生服务。2005 年美国国家卫 生信息网开始建设区域信息化平台的全国 卫生信息网络架构原型,通过发展电子医 疗信息技术系统, 以减少医疗差错, 挽救 生命和节省资源 ${ }^{[4]}$ 。

2013 年 9 月, 国务院颁布《关于加 快发展养老服务业的若干意见》将积极推 进医疗卫生与养老服务相结合列为加快发 展我国养老服务业的六大任务之一, 强调 “推动医养融合发展, 探索医疗机构与养 老机构合作新模式”。2015 年 3 月, 国 务院办公厅印发《全国医疗卫生服务体系 规划纲要（2015-2020 年）的通知》，单 列章节强调发展 “医养结合”，提出 “发 展社区健康养老服务, 提高社区卫生服务 机构为老年人提供日常护理、慢病管理、 康复、健康教育和咨询, 中医养生保健等 服务的能力, 鼓励医疗机构将护理服务延 伸到居民家庭”。政策文件的出台为我国 医养结合养老模式的发展创造良好的制度 环境。

养老机构服务的对象为高龄、高危人 群, 属于高风险的服务行业, 其本质属性 决定养老机构具有投资大、见效慢、利润 低、风险大的特点 ${ }^{[5]}$ 。如何规避养老服务 中的服务风险, 减轻养老机构因服务风险 而造成的经济损失，是每一个养老机构都 面临的问题。由于企业集团内部成员公司 众多且关联关系复杂，如果企业集团不能 有效控制其整体信用风险，或无法正确识 别和监管客户的信用风险, 则企业的经营 和融资能力都将受到极大的限制 ${ }^{[6]}$ 。养老 机构内部各成员间存在关联关系及交互作 用，使其成为复杂的适应系统，因此对其
信角)(险管控的研究应从复杂系统的视角 出发进行探索。

“医养结合”是近年来在我国逐渐发 展起来的一种新型养老模式 [7], 其将现代 医疗服务技术与养老服务有效结合, 实现 “有病治病, 无病疗养” 的养老保障模式 创新 ${ }^{[8]}$ 。该模式已经成为 “十三五” 时期 重点培育和发展的养老服务新方向。发达 国家养老服务体系改革历程, 服务整合和 养老机构转型是必然趋势。为破解失能老 人养老难题, 必须利用机构养老模式创 新, 鼓励养老机构增强医护功能, 改善失 能老人健康状况, 利用政策创新, 实现医 疗和养老资源的整合, 推动医养结合养老 机构的发展。发达国家的居家养老模式和 相关配套体制均已经发展较成熟，对我国 构建医养结合养老机构创新模式有一定借 鉴意义。

随着年龄增长、身体机能的衰退, 老 龄人群具有巨大的医疗保健服务需求。而 我国老龄人口中, 失能老人、高龄老人、 空巢老人的数量也在快速上升。失能风险 是老年人除了疾病风险外另一项较高的风 险, 失能老人是指由于身体机能衰退或者 健康状况恶化等原因丧失生活自理能力的 老人。2010 年底, 中国部分失能和完全 失能老人达到 3.3 千万, 到 2015 年达到 4 千万[9]。照护需求增长速度加快, 但长期 照护的社会服务明显不足, 失能老人需要 长期照护的医养结合服务。医养结合养老 服务中的 “医” 指医疗康复保健服务, “养”包括生活照护、精神心理卫生服 务、文化活动服务等[10]。医养结合养老模 式集医疗、康复、养生及养老等为一体, 将养老机构和医院的功能相结合, 把老人 的日常照护和治疗康复融为一体的新型养 老服务模式, 可实现社会资源利用的最大 化 ${ }^{[11]}$ 。

\section{2. 养老机构行业风险分析}

由于老年人的健康状况具有较高的不 确定性, 为其提供养老和医疗服务时存在 出现意外事故及医疗事故的风险。且医养 结合养老院是新兴的行业, 如何识别和测 度医养结合养老机构运营的风险? 如何有 效地进行老年人健康风险管控, 进而提升 


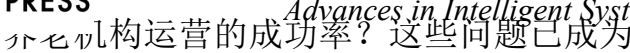
我国养老机构产业发展过程中面临的突出 问题。医疗风险就是在医疗工作中各种各 样的不安全因素, 也是医疗人员对患者发 生医疗侵权行为所负的法律和经济赔偿等 责任的风险 ${ }^{[12]}$ 。所有医疗过程都是风险和 利益并存, 且贯穿诊断、治疗和康复全过 程 ${ }^{[13]}$ 。风险管理通过对风险进行识别、衡 量、分析, 并有效处置, 以最低成本实现 最大安全保障, 减少风险事件发生, 从而 有利于确保患者安全, 提高医疗服务质量 [14]。

(1)养老机构信息化程度低, 存在信 息孤岛现象。我国养老体系建设较晚, 医 养结合养老机构在发展中存在不少问题。

信息化及互联网发展, 已经步入云计算平 台及大数据时代 ${ }^{[15]}$ 。目前养老服务机构普 遍存在信息化程度低, 缺乏长期有效的合 作交流平台, 社区居家医养结合处于探索 阶段, 信息不完善。我国养老服务机构相 互独立，彼此竞争，各机构间合作交流较 少, 更缺乏数据资源共享的情况, 这样造 成一定程度的医疗、养老资源的浪费。因 老年人身体状况信息的闭塞，可导致老年 人只在一个医养结合的养老机构, 出现转 诊困难现象。因而 “信息孤岛”现象阻碍 老年人对医养结合养老模式的需求, 造成 医疗资源浪费, 不利于医养结合养老服务 产业的可持续发展。

(2)养老机构服务定位不清及违规操 作。作为养老模式的创新探索, 准确定位 是 “医养结合” 能健康、快速发展的重要 保障 ${ }^{[16]}$ 。目前, 具备公立、民营大型及专 业化较高等特点的养老或医疗机构因为自 身已有的基础, 能顺利开展医养结合的业 务, 但也有已经开展医养结合的服务机构

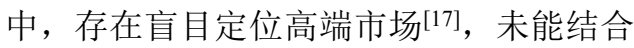
本地区社会经济发展水平、人口结构及消 费水平等实际养老需求, 从而影响养老机 构使用率。

在 “医养结合” 养老模式实践中，存 在较为严重的 “套保” 风险 ${ }^{[17]}$ 。在部分已 经纳入基本医疗保险试点且开设养老、托 老服务的民办医疗机构中，存在把 “养老 床位” 变相改为 “医疗床位”, 套用医保 资金支付养老床位费; 将入住老人一般的 康复护理服务变相改为 “医疗诊断治
Research (AISR) 保基金报销费用, 用医保给老 人开保健处方, 变相套取医保资金。以上 违法、违规行为不仅严重影响医疗保险资 金的正常使用, 且侵蚀医疗保险基金, 损 害其他参保人员的权益, 增加爱养老机构 和医疗机构的合作难度。

(3)主管部门交叉重叠, 责任边界不 明确。医养结合养老机构不同于传统养老 模式具有明确的责任主体, 如机构养老的 责任呢主体是公办或民办养老机构, 而居 家养老的责任主体是家庭, 而医养结合养 老机构的主任主体归属是多元的 ${ }^{[17]}$ 。在实 践中, 有设有老年科病房的医疗机构开展 医养结合养老服务, 也有医疗机构下属或 者分设的养老服务单位, 还有与医疗机构 合作开展的福利院和养老院、以及开展家 庭访视的社区卫生服务中心等形式。根据 各地养老机构运营现状看, 业务主管部门 部分交叉重叠, 责任边界不清晰是当前医 养结合养老模式实践中面临的最大困难 [18]。机构管理部门的交叉重叠管理的现象 会导致医养结合养老机构处于多部门治理 的现象, 但各管理部门间职责不明晰, 管 理界限不清楚, 容易出现利益纷争, 责任 推诿, 从而对医养结合养老机构的健康发 展造成阻碍。多元化的责任主体使 “医养 结合” 的模式超越传统养老模式的范畴, 作为一种新的养老服务供给方式可以和不 同养老模式相结合, 实现综合的医养结合 的老人服务。

(4)养老机构中因医疗活动导致的风 险。

1) 岗位设置中的医疗风险。医院岗 位设置是人力资源部门对医疗工作分析的 基础上, 确定医院需要岗位的类别和数 量, 体现养老机构发展现状和未来趋势及 岗位间的流程关系, 是聘任医务人员的前 期工作。科学合理的医疗人力资源配置, 明确职责的岗位设置, 可提高医疗工作的 安全性。而医疗职责设置不合理, 可能导 致后来的医疗管理混乱, 造成重复劳动与 无人问津并存的现象。养老机构人力资源 管理者对医疗工作初始状态的敏感, 是后 来医疗工作安全的重要前提。医务人员数 量严重不足, 超负荷工作, 科室医疗人员 配置不合理或分工协调不当会导致医疗风 险的出现。有效合理的医疗岗位设置、合 


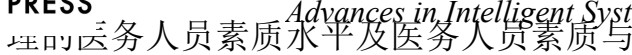
岗位要求达到 “人岗匹配” 会促进临床医 疗效果, 提高养老机构效率。

2）养老机构管理工作中的风险。在 医疗管理中, 医疗管理制度不健全, 措施 不力, 监督不严, 缺乏业务技术培训及医 疗管理人员对存在的不安全因素缺乏敏感 性和预见性, 都是导致风险产生的原因。 大多数医养结合养老机构缺乏足够的医疗 资源, 未按统一的诊疗规范路径进行治疗 护理, 可导致机构老年人需要医疗帮助 时, 最佳诊疗疗效难以实现。医养结合养 老机构值班及交接班制度不良，导致缺乏 关键岗位人员在岗，其机构老年人医疗问 题难以解决。医养结合养老机构工作人员 医疗护理理念，医疗照护技术水平，与机 构老人照护效果关系密切。医养结合养老 机构管理中缺乏风险管理理念的工作人员 及管理人员, 各层管理效果和管理组织难 以有效运行。

3）医疗服务中环境及设备因素导致 医疗风险。物理环境直接影响患者的身心 舒适和治疗效果, 患者希望得到最佳的医 疗服务, 希望在安全、舒适、优雅的环境 中接受诊疗和修养 ${ }^{[19]}$ 。在养老机构医疗工 作中, 药品品种和数量不足、质量差或失 效, 医用危险品管理和使用不当, 医疗器 械与设备不全、性能不佳、维护不好、规 格不配套等, 都会直接影响医疗技术的正 常发挥、延误治疗, 影响医疗效果, 形成 潜在的医疗风险。因此养老机构在建筑布 局、工作流程、消毒隔离等方面应有科学 合理的设计和安排。根据建设部、民政部 联合颁布《老年人建筑设计规范》，对老 年人的起居室、卧室、厨房、卫生间、阳 台、走道等基础设施的面积、高度及形状 等严格按照国家相关规定建设和改造无障 碍设施, 确保养老机构设施规范安全。

\section{3. 风险管理策略}

（1）建立健全规范的养老机构管理制 度, 制订相关老人院管理预案。医养结合 养老机构与服务对象的关系从法律角度看 是合同关系，机构提供养老服务，老人使 用养老服务。合同各方都应依据法律法规 享受一定的权利和履行一定义务。与养老

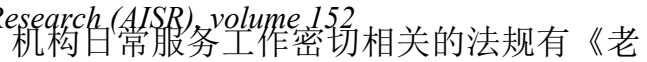
年人权益保障法》和《老年人社会福利机 构基本规范》。Luquire 提出建立医疗风 险管理委员会来专门研究现实的和潜在的 医疗风险, 同时建立相关消除或减少风险 的教育培训程序, 以预防医疗风险及确保 医疗质量提高 ${ }^{[20]}$ 。管理者制定重点风险管 理应急预案, 以应对和处理突发事件。赫 伯特 - 西蒙的 “有限理性” 决策模型认为 在复杂的环境中, 人不可能做出最优的决 策, 而只能做出最满意的决策 ${ }^{[21]}$ 。管理者 建立健全临床医疗风险管理程序, 不良事 故报告程序, 危险和差错管理方案, 通过 分析医疗风险的构成因素, 收集资料、分 析数据、报告和评估临床医疗活动中的不 良事件, 对医疗风险进行识别、评价、处 理和再评价, 将信息反馈到临床医疗实践 中, 进行针对性修改和改进, 以帮助医疗 工作者做出最满意的决策。

(2)按风险管理阶段进行养老机构风 险防范。风险管理包括四阶段, 即风险识 别、风险衡量与评价、风险处理及风险管 理效果评价。风险识别是对潜在和客观存 在的各种医疗风险开展系统地连续识别和

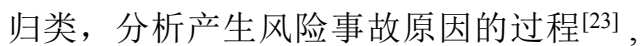
是整个风险管理的基础。风险评价对医疗 风险进行定量分析和描述, 对风险发生可 能性和可能造成损失的严重性进行估计, 包括风险发生概率、损失程度、风险事故 发生的可能性及危害程度, 确定危险等 级, 为采取相应风险措施提供决策依据 [28]。风险处理是医疗风险管理的核心内容, 是在风险识别、风险评价基础上采取的应 对风险事件的措施 ${ }^{[19]}$ 。风险管理效果评价 实质是信息反馈的过程, 是对风险处理手 段的适用性和效益性进行分析、检查、修

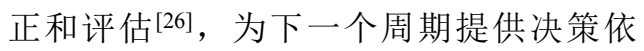
据。养老机构风险管理中应注重信息交流 和咨询, 信息交流和咨询可分解、转移及 降低相关风险, 是在风险管理中每一环节 均需贯穿的重要内容。

(3)开展有效的继续教育途径, 提高 医务人员风险防范意识。提高工作人员安 全服务意识, 引进社工专业人才, 增强机 构中老人的自我安全保护。提高工作人员 的安全服务意识, 增强处理突发问题的应 急能力。医养结合养老机构在制定科学 
儿、烦范化工作流程的基础上，不断加强 工作人员安全服务意识, 提高安全服务技 能, 增强处理突发问题的应急能力, 及时 发现问题、解决问题。

Greene 认为提高对医疗风险的认识是 减少医疗风险的前提, 且要不断进行管理 干预来解决这一问题[21]。通过继续教育规 范医务人员职业行为, 提高整体素质, 降 低风险。研究表明护龄 $\leqslant 3$ 年的护士由于 临床实践经验减少, 发生医疗缺陷的相对 风险度是护龄 $>3$ 年护士的近 18 倍 ${ }^{[27],}$ 提示医疗管理者应关注低年资护士的继续 教育, 国内文献尚未报到医生的类似数 据, 值得后续研究。美国伊利诺州护理协 会指出预防护理差错发生的方法, 最重要 的就是要对护理人员落实病人安全知识的 职前训练和在职教育 $[28]$ 。随着社会的进步 和医学的发展, 医疗工作中涉及的法律及 伦理问题越受到重视。养老机构应根据养 老机构需求及医务人员的素质开展有针对 性的培训活动如《执业医师法》《护士条 例》《侵权责任法》《病历书写基本规 范》等, 加强教育强化医务人员风险意 识。其中医生和护士是处在医疗风险第一 线的具体执行者，强化医护人员风险意 识, 提高鉴别和化解风险的能力是开展医 疗风险管理的关键。

(4)建立清单式管理, 降低非技术风 险。现代世界的复杂性已经超出人力所能 控制的范围, 使用清单, 就是为大脑搭建 起一张 “认知防护网”, 它能够弥补人类 与生俱来的认知缺陷, 如记忆不完整或注 意力不集中 ${ }^{[18]}$ 。所谓清单式管理, 是指针 对某项职能范围内的管理活动, 分析流 程, 形成清单, 明确控制要点, 检查考核 按清单执行。它方便快捷地反映出动态化 的痕迹, 能追溯到整个管理过程的来龙去 脉 ${ }^{[29]}$ 。清单是理性选择后的思维工具, 突 出关键环节，不仅是基准绩效的保证，还 为基准绩效建立了更高的标准。清单可帮 助医护人员记忆关键步骤, 清晰列出操作 过程中必不可少的环节。优秀的清单要求 精确、高效、切中要害, 即便在最危急的 情况下也便于使用。清单的目标是要培养 注重合作和纪律的文化 ${ }^{[18]}$ 。因此严格控制 微小事件的发生是解决风险管理中的最佳
方案, 吕宬本最尔，可把风险消除在萌芽状 态 ${ }^{[30]}$ 。

(5)设立保险制度及医疗风险基金, 建立风险共担机制。医疗风险基金是养老 机构为规范处置由医疗过失、过错等因素 给养老机构造成损失而设立的准备基金, 宗旨是支持新技术和大型风险性较强手术 的开展, 营造宽松的医疗环境, 以提高医 疗服务质量 ${ }^{[30]}$ 。在当今商业医疗保险制度 尚不健全的条件下, 养老机构通过设立医 疗风险基金, 建立风险共担机制, 增加养 老机构主动进行风险预防和控制的能力。 医疗风险基金应结合医院财务管理, 规范 核算、合理运用，并实行监督考核机制， 确保医疗风险管理机制得以持续发展 ${ }^{[31]}$ 。 养老机构通过设立医疗风险基金充分调动 科室风险管理者的积极性, 减少医疗行为 及系统组织上的医疗风险, 实施有效的诊 断治疗护理程序，提高患者的诊治效益， 同时保障医务人员的医疗工作顺利进行, 规避医疗风险并减少医疗风险引发的医疗 纠纷, 对养老机构的整体管理水平起到积 极的作用。

利用大数据、信息化、智能化, 开展 有效的养老机构监管, 履行政府责任, 加 快行业自律。医养结合医疗机构人员应关 注医疗活动中的潜在风险, 应用有效的风 险管理手段最大限度地杜绝或减少风险的 发生, 维护患者的安全, 为养老机构老人 及养老机构实现双赢。

\section{参考文献}

[1] Department of Health. The National Program for IT in the NHS[R]. Twentieth Report of Session 2006-2007, the Committee of Public Accounts,2007.

[2] Mary,J,G,Steven,R.G.\&Sheel,M.P.,Long -term Care in Developed Nations:a Brief Overview[R].The AARP Public Policy Institute, 2003.

[3] 王淑, 王恒山, 王有光. 面向资源优化配 置的区域医疗协同机制及对策研究 $[\mathrm{J}]$. 科技进步于对策, 2010(20):38-42.

[4] 北京大学中国经济研究中心卫生经济 学组. 美国医疗系统的改革和启示. 中 国医疗卫生体制改革研讨会, 北 京. 2008 . 
LU」T国养老机构发展研究报堡. 应对老老龄

化 我国养老机构须再定位. 中国医院 院长. 76-78.

[6]徐超, 周宗放. 基于 CANK 模型的企业 集团信用风险适合度景观仿真. 系统工 程. 2016, 34（1）：147-153.

[7]李超. 智慧城市背景下社区养老服务智 能化研究 $[D]$. 上海: 上海工程技术大 学, 2015.

[8] 孟渘颖. 医养结合，养老模式面临的挑 战 $[\mathrm{N}]$. 中国劳动保障报, 2015 , (7) : 29.

[9] 马丽丽, 陈娜, 汤少梁. 医养结合养老 机构养老服务发展政策研究. 医学与社 会. 2016（29）4：40-43.

[10］符美玲, 陈登菊, 张伟等. 从长期 住院研究谈构建 “医养结合” 照护体 系的必要性 $[J]$. 中国医院, 2013, 17 (11) : 21-23.

[11］黄佳豪，孟昉。“医养结合”养老 模式的必要性、困境与对策 $[\mathrm{J}]$. 中国 卫生政策研究, 2014, 7 (6) : 63-68.

[12］李小燕. 医疗风险及风险医疗成本 管理的探讨 $[\mathrm{J}]$. 中国实用医疗杂志, 2012,28 (5) : 72-73.

[13］陈辽平 香港医院的医疗风险管理 [J]. 中国医院管理, 2000, 9(20)：6162.

[14] Aufseeser weiss MR , Ondeck DA.Medication use risk management:Hospital meets home care[J] . Journal of Nursing Care Quality, 2001, 15(2):50-57.

[15］李宁，张迟，王雷等. 湖北省构建 免疫规划信息管理系统大数据分布式 云计算平台初探。中国疫苗和免 疫. 2017（23） 8:429-435.

［16］封进，何立新. 中国养老保险制度 改革的政策选择一一老龄化、城市 化、全球化的视角 $[\mathrm{J}]$. 社会保障研 究，2012（3）：29-41.

[17］孟颖顷. 我国 “医养结合” 养老模 式发展的难点及解决策略. 经济纵 横. 2016（7）：98-102.

[18］符美玲, 等. 从长期住院研究谈构 建 “医养结合” 照护体系的必要性 $[\mathrm{J}]$. 中国医院，2013（11）：21-23.
[19] 杳乐寒, 尚少梅. 基础医疗学. 人民 卫生出版社: 2012 .

[20］孔鹏, 方鹏塞, 杨凌. 医疗风险管 理研究 $[J]$. 医学与社会. 2006, $19(4)$ : 44-45.

[21］王慧. 高校教师职务聘任管理中的 “蝴蝶效应” [J]. 黑龙江高教研 究. 2006，151（11）：80-82.

[22］李亚洁, 张立颖, 李瑛, 等. 风险管 理在医疗管理中的应用 $[\mathrm{J}]$. 中华医疗 杂志. 2004, 39 (12) : 918-920.

[23］吴大勇. 呼吸机应用中的医疗风险 及其防范 $[\mathrm{J}]$. 中国循证医学杂 志. 2006，6（1）: 6-8.

[24] 廖微菁. 医疗风险管理的研究进展 [J]. 中华医疗杂志. 2007, 42 (9) : 830832.

[25] American College of Cardiology Foundation/American Heart Association Task Force on Practice Guidelines, American Society of Echocardiography, American Society of Nuclear Cardiology, et al.2009 ACCF/AHA focused update on perioperative beta blockade incorporated into the ACC/AHA 2007guidelines on perioperative cardiovascular evaluation and care for noncardiac surgery.J Am Coll Cardiol,2009,54(22);el3-el18.

［26］张小钗. 低年资护士发生医疗缺 陷的原因及对策 $[\mathrm{J}]$. 医疗与康 复, 2004, 3(4) : 272-273.

[27］陈玉芝. 从护理照顾层面谈病人 安全 [J]，台湾医学, 2004, 8(4): 528-534.

[28］朱彦体. 借助清单式管理提升中小 学中层执行力 $[\mathrm{J}]$. 教学与管理, 2012. 12: 13-15.

[29］杨胜远. 风险管理中的 “蝴蝶效 应”及其对策 $[\mathrm{J}]$. 煤炭经济研 究, 2008, (11) :61-62.

[30］杨勇, 柴长春. 设立医疗风险基 金的作用和意义 $[\mathrm{J}]$. 解放军医院管理 杂志，2006，13（5）：436-437.

[31] 武敏. 医疗风险基金在医院财务管 理中的应用 $[\mathrm{J}]$. 中国医院管理, 2011, 31 (11) :67-68. 